\title{
Image Spotter
}

Anamika Bhadra ${ }^{1}$, Debarup Das ${ }^{2}$, Pallavi Mahato ${ }^{3}$, Yashpal Yadav ${ }^{4}$, Atanu Chandra

Bengal Physician Journal (2020): 10.5005/jp-journals-10070-7035

\section{Figure 1: Background}

This 32-year-old female presented to the outpatient department with the complaint of occasional chest pain on exertion for the last one month. She had a history of anterior wall myocardial infarction (AWMI) for which primary percutaneous coronary intervention (PCI) in the left anterior descending artery (LAD) was done at the age of 27 years. She had also a family history of ischemic heart disease. On examination, there was xanthelasma and corneal arcus. Multiple non-tender subcutaneous nodules, attached to tendons over the dorsum of both hands and legs were present (Fig. 1). She had been diagnosed as a case of familial hypercholesterolemia in 2016, at the time of her diagnosis with acute myocardial infarction (AMI), and started on medications.

Final diagnosis: Tendon xanthoma in a case of familial hypercholesterolemia.

(Acknowledgment: Anamika Bhadra, Department of Internal Medicine, Medical College, Kolkata, West Bengal, India)

\section{FIgURE 2: BACKGROUND}

A 35-year-old male patient complained of fever, periorbital rash, and proximal muscle weakness for the last 8 months. On examination, a bilateral symmetric periorbital erythematous rash associated with lid edema was noted without any other obvious skin lesions (Fig. 2). There was associated proximal muscle weakness in both the upper and lower limb. Investigations revealed a high creatine kinase, electromyography suggested myopathic pattern, while magnetic resonance imaging (MRI) quadriceps showed muscle atrophy. Muscle biopsy revealed features suggestive of inflammatory cell infiltration and perifascicular atrophy. Malignancy and connective tissue disease screen were negative. Based on these features, dermatomyositis was diagnosed and he was started on steroids and immunomodulators.

Final diagnosis: Heliotrope rash in a patient with dermatomyositis. (Acknowledgment: Pallavi Mahato, Department of Internal Medicine, Burdwan Medical College and Hospital, Bardhaman, West Bengal, India)

\section{FIgURE 3: BACKGROUND}

A 55-year-old female presented with brownish discoloration over the anterior aspect of the left leg without any associated symptoms for the last 2 months. On examination, there was a reddish-blue net-like cyanotic pattern suggestive of livedo reticularis (Fig. 3 ).

\footnotetext{
1,2Department of Internal Medicine, Medical College, Kolkata, West Bengal, India

${ }^{3}$ Department of Internal Medicine, Burdwan Medical College and Hospital, Bardhaman, West Bengal, India

4,5 Department of Internal Medicine, RG Kar Medical College and Hospital, Kolkata, West Bengal, India
}

Corresponding Author: Atanu Chandra, Department of Internal Medicine, RG Kar Medical College and Hospital, Kolkata, West Bengal, India, Phone: +91 9474190374, e-mail: chandraatanu123@gmail.com

How to cite this article: Bhadra A, Das D, Mahato P, et al. Image Spotter. Bengal Physician Journal 2020;7(3):72-73.

Source of support: Nil

Conflict of interest: None

Livedo reticularis (LR) is thought to be caused by disturbances in the cutaneous blood flow that may occur in a variety of physiological or pathological conditions. Primary LR is more common in females and may be associated with painful ulceration called atrophie-blancheen-plaque. Secondary LR may be associated with atheroembolism, systemic lupus erythematosus (SLE), and other vasculitides, antiphospholipid antibodies, hyperviscosity, cryoglobulinemia, and Sneddon's syndrome (ischemic stroke and livedo reticularis).

(Acknowledgment: Yashpal Yadav, Junior Resident, Department of Internal Medicine, RG Kar Medical College and Hospital, Kolkata, West Bengal, India)

\section{Figure 4: Background}

An 18-year-old male patient presented to the outpatient department for routine follow-up of seizure disorder. He was on phenytoin (100 mg orally thrice a day) for the last 6 years. Examination of the oral cavity revealed gingival hypertrophy (Fig. 4). Drug-induced gingival overgrowth, also known as drug-induced gingival enlargement, is a well-known adverse effect of a few drugs, such as anticonvulsants, immunosuppressants, and calcium channel blockers. Among the anticonvulsants, phenytoin (PHT or 5,5-diphenylhydantoin), phenobarbitone, sodium valproate, primidone, and ethosuximide are commonly associated with gingival hypertrophy.

Final diagnosis: Phenytoin-induced gingival hypertrophy.

(Acknowledgment: Debarup Das, Department of Internal Medicine, Medical College, Kolkata, West Bengal, India)

\footnotetext{
(c) The Author(s). 2020 Open Access This article is distributed under the terms of the Creative Commons Attribution 4.0 International License (https:// creativecommons.org/licenses/by-nc/4.0/), which permits unrestricted use, distribution, and non-commercial reproduction in any medium, provided you give appropriate credit to the original author(s) and the source, provide a link to the Creative Commons license, and indicate if changes were made. The Creative Commons Public Domain Dedication waiver (http://creativecommons.org/publicdomain/zero/1.0/) applies to the data made available in this article, unless otherwise stated.
} 

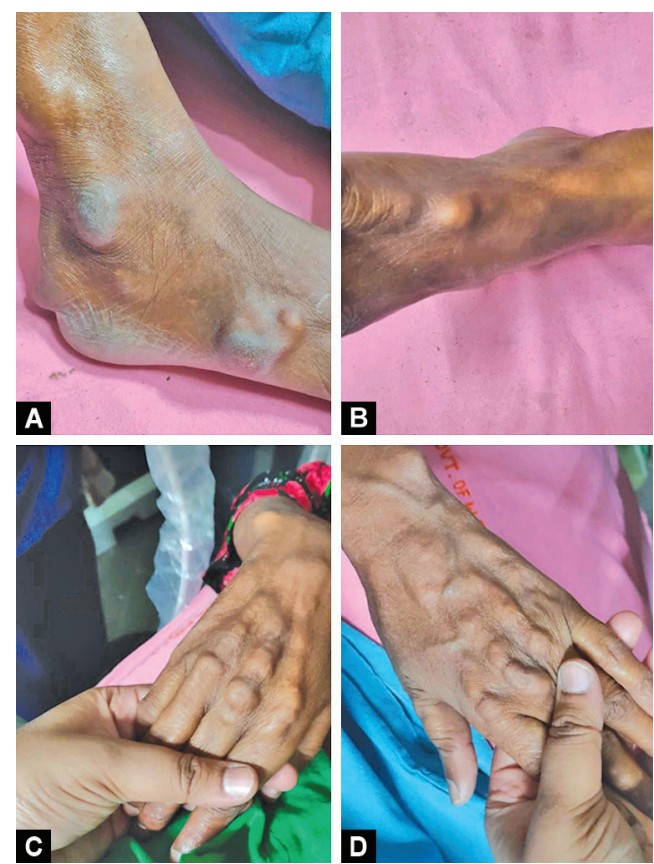

Fig. 1:

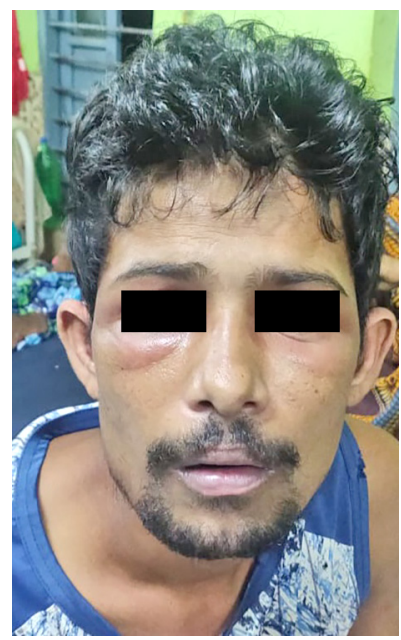

Fig. 2: 